\title{
Make New Critical Stories. A View on the 2017 Chicago Architecture Biennial
}

\section{Maurizio Sabini}

Exhibition Review / CRITICISM

ABSTRACT - The 2017 edition of the Chicago Architecture Biennial, Make New History, like any other similar event, has caused debate and controversy. Beyond inevitable flaws and shortcomings, the CAB though deserves to be appreciated for the quality of most of the exhibited projects, works or installations, some of which managed also to offer what was missing in this CAB's main theme: a critical perspective. The theme itself of the $C A B$ is challenged, but the good works of many international architects and artists, well selected by the Artistic Directors Sharon Johnston and Mark Lee, is appreciated for their contributions to a critical discourse in our field, for their "critical stories." Through a discussion of the curators' hypothesis and of some of the most interesting works, as well as of some critical contributions included in the exhibition catalog, this review tries to offer a critical assessment for an event that, fortunately, has already acquired an outstanding position within the architecture cultural landscape of our time.

Keywords: Chicago Architecture Biennial, architecture exhibition, critical call, post-modernism, modernism

Events such as the Chicago Architecture Biennial want to provoke thoughts, ideas, debates and interest on certain cultural themes. In spite of some inevitable shortcomings (which have attracted though some unjustified 
criticism), the second edition of the CAB does just that.

As for other similar events in the past, it is quite easy to critique this or that show, section, exhibition item or project, or even the approach of the curators or the event itself. No biennial, triennial or similar event can be considered a complete success. The Venice Architecture Biennial of 1980, the "Strada Novissima," curated by Paolo Portoghesi, which in fact inaugurated the following series and multiplication of architecture biennials, had a grand and global resonance. It still brings though with it the mark of its "original sin," that is of sanctioning (and, worse, promoting) the advent of Post-Modernism, which cannot be really regarded as a bright and inspiring moment in the evolution of twentieth century architecture, no matter how interesting (for some) its linguistic explorations might have been. Yet, that biennial sparked debate, stirred the professional and public discourse. It might have had even the undesired effect of inviting new reflections and research on the "Modern project." It provoked thought. And that is good for architecture, as we need to continue to stimulate critical thinking and cultural repositioning for the success of our field and the growth of our knowledge. The moment architects stop thinking, and using architecture as a powerful critical tool for the betterment of our society and environment, the profession and the body of knowledge in the field risk to find themselves again stuck in the quicksand of cultural and social irrelevance.

If this $C A B$ has any limit, it is precisely that one of not posing a critical enough question. The hypothesis of the curators, Sharon Johnston and Mark Lee, with the CAB's theme Make New History, is that there exists a young generation of architects "that believes in continuity... [without carrying] the stigma of postmodernism... [and that] for them, history is a treasure trove. They don't feel shame or guilt to retrieve from it." ${ }^{1}$ It is an hypothesis that sounds too conciliatory, reassuring, somewhat simplistic (who belongs to such generation?) and superficially common-sense. When did architecture, like any other form of art, stop to reflect on history? As it has been widely demonstrated (for example, by Robert Venturi and Denise Scott Brown in their research on the "forgotten symbolism of architectural form" - Learning from Las Vegas, 1972), even the Modernists, who ideologically rejected any notion of debt towards history, borrowed heavily from other artistic precursors or contemporaries, as well as from the larger imagery and culture of the industrial world.

When Mark Lee states that "we see history as a horizon, open and accessible, with multiple entry and exit points. ... where the old and the new are in a cyclical relationship, or when the old becomes new when viewed through contemporary knowledge," ${ }^{2}$ he is not proposing a particularly novel approach. How did Venturi approach the study of "complexity and contradiction" in architecture? Or even what was the meaning of Le Corbusier's statement "I have only one master: the past"? 
Moreover, there is the broader concern that such "return to the core" of the discipline, as this CAB seems to suggest, after years of much engagement with social and environmental issues (as demonstrated, for example, by the 2016 Venice Architecture Biennal curated by Alejandro Aravena), risks to return architecture to the arid terrain of a supposed disciplinary purity. As aptly pointed out by Christopher Hawthorne:

Is it possible to have a return to history in architecture that's apolitical, or political only within the field itself? Is it wise? We tried that at least once before, in the 1980s, as postmodernism softened in its middle age from an insurgent movement powered by theory to a largely decorative and scenographic one. I'm not sure we want to take that path again. Especially not right now. ${ }^{3}$

Indeed, the theme of this CAB is not particularly innovative, nor it can represent a new perspective on a supposedly emerging phenomenon. This $\mathrm{CAB}$, however, provokes thought in the wider public and it did provoke thought in all participants, with many interesting responses. The value of this $C A B$, in other words, should be found more in the specific, (critically) intelligent reactions by particular architects, designers and artists for their works in themselves, rather than in how well they responded collectively to the charge of the curators. And having provoked those contributions goes anyway to the credit of Johnston and Lee, more than having posed a rather ambiguous and unconvincing question.

In fact, it is the "critical" perspective that is missing in their question, and it is precisely the perspective that some interesting responses have been able, perhaps unsolicitedly, to offer: new "critical stories."

Examples of such critical stories, just to name a few, include: Tatiana Bilbao's tower for the re-run of the 1922 Chicago Tribune competition (more interesting as a critique of the tall building than as an entry for a trite exercise - the Chicago Competition re-run was already experimented in 1980 under Stanley Tigerman's direction); MAIO's reflection on Marcel Duchamp's ambiguous and fascinating "dual door" for his Paris apartment; Iñigo Manglano-Ovalle's installation posing the disquieting question of whether Modernism has really left us (or could it return with the power of its vision) - hence Constantin Brancusi's sculpture replica upside down, poking through the conciliatory grid of our world; ZAO/Standardarchitecture's "hutong metabolism," critically reflecting on the dilemma of development vs cultural preservation in China; Iñaki Abalos' patient research into the ethos of a place with his Planta Project for the Sorigué Foundation in Spain, done in collaboration with Renata Sentkiewicz and Armin Linke; or Keith Krumwiede's speculative diagram "Visions of Another America," which re-visits the questioning power of FLW's Broadacre City in contemporary 
terms, provocatively assembling types of developer homes on an ideal grid for an improbable "realistic utopia."

Examples include also artists, such as photographer Luisa Lambri, who invites us to re-appreciate the vision of Modernism through her interior photography of Mies' Farnsworth House - incidentally, the less than satisfactory displays of both Krumwiede's and Lambri's works are examples of the curatorial spatial challenge posed by the Chicago Cultural Center:

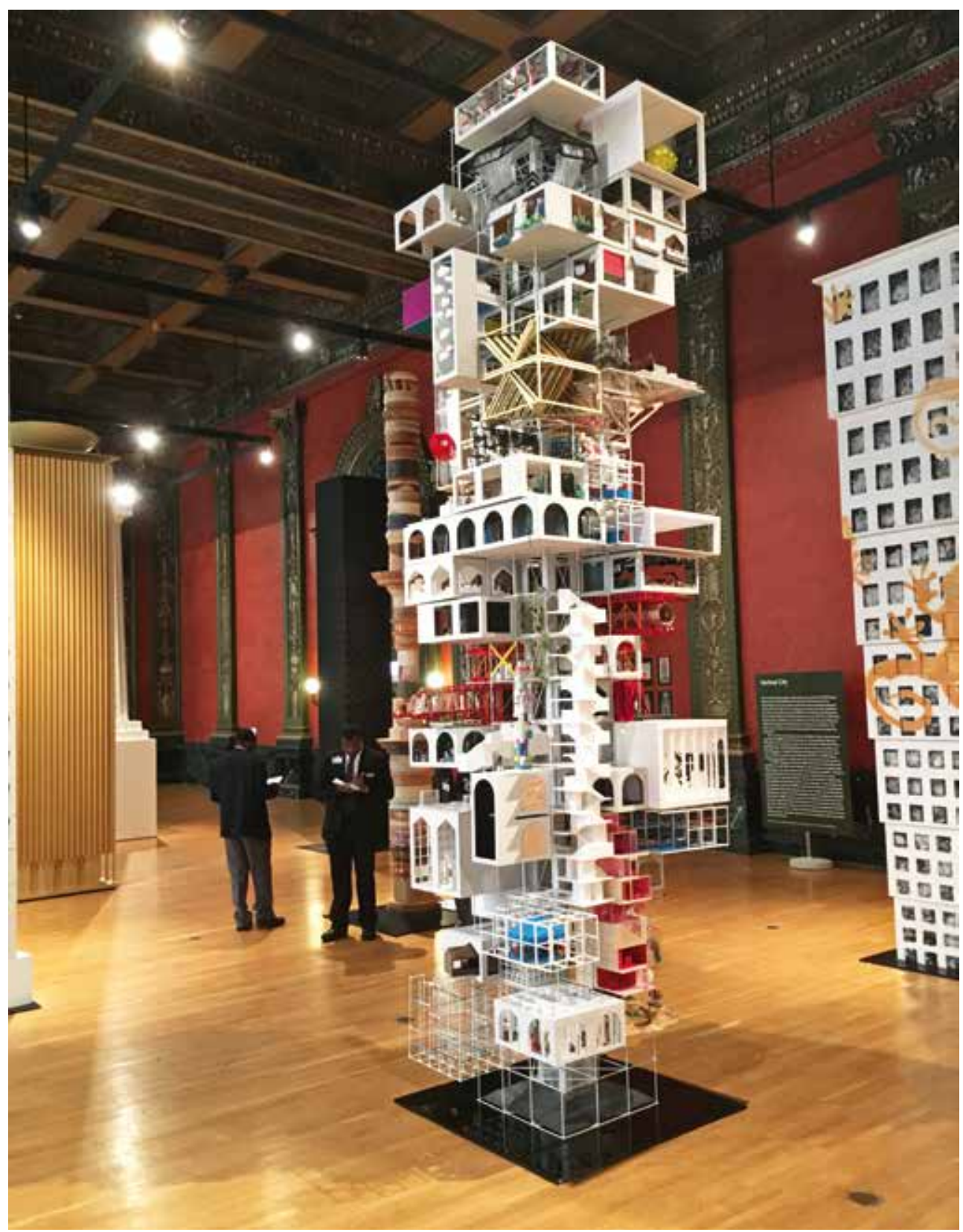

Figure 1. (Not) Another Tower, by Tatiana Bilbao Estudio, Mexico City (Mex.), for the CAB's section "Vertical City." The section features the works of sixteen architects from around the world invited by the curators to re-imagine the brief of the 1922 Chicago Tribune Tower design competition. 
contrary to Johnston's claim that "what is powerful about the Biennial taking place at the Cultural Center, is that it is already a community building," ${ }^{4}$ I agree with Aaron Betsky, for whom "no matter how grand it is, [... the Chicago Cultural Center is.... ] particularly bad place for any exhibition, because of its disjointed layout." 5

Lambri's photographs are only the most striking art pieces in a very interesting section dedicated to photography, A Love of the World, curated

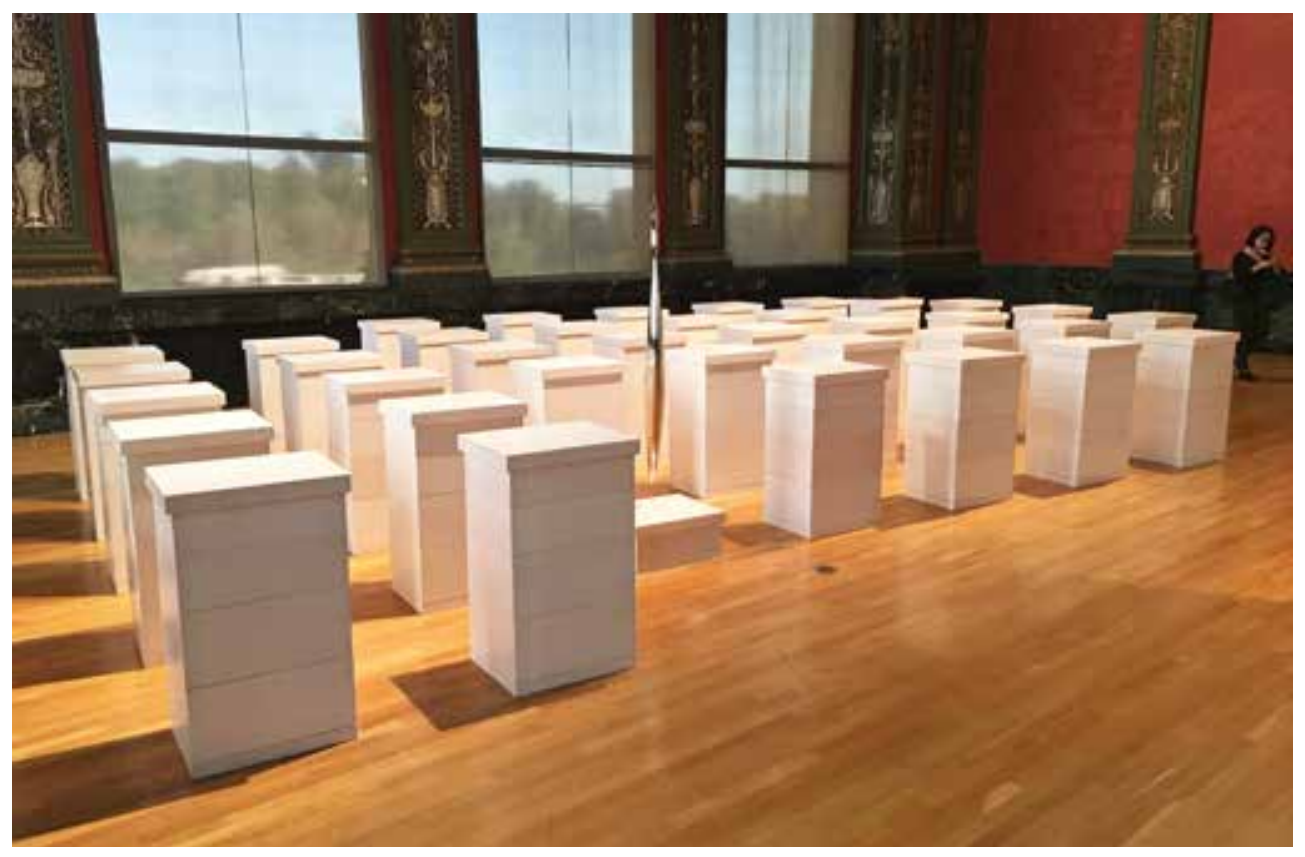

Figure 2. Beehives with Asteroid, 2013-17, by Iñigo Manglano-Ovalle, Chicago.

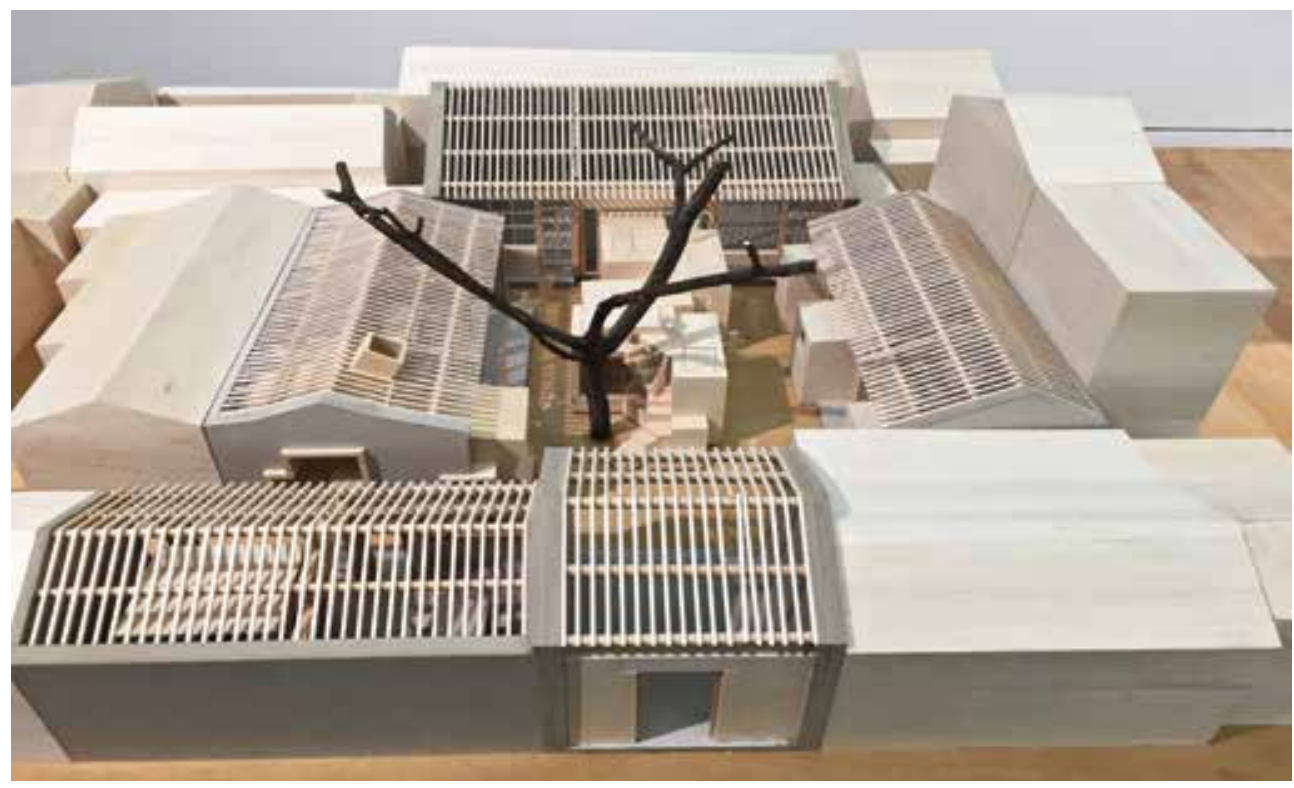

Figure 3. Make New Hutong Metabolism, Beijing, by ZAO/standardarchitecture, Beijing. 
by Jesús Vassallo. This section wants to "present a kaleidoscopic view of architecture and the city where the ideas of the discipline and the artifacts of the world find new fertile common grounds." ${ }^{6}$ With photographs by Lambri, Philipp Schaerrer (Chicago Series) and others, this section becomes a reflective mirror of architecture's impact on the world, through which one can measure the differential between our aspirations, ideals, visions, and the reality of our environment.

The proposal [of $A$ Love of the World] is that, in order to effectively reintroduce history as a working material for architects today, we must also adopt an understanding of architecture as being, at any point in time, part of a larger material culture. ${ }^{7}$

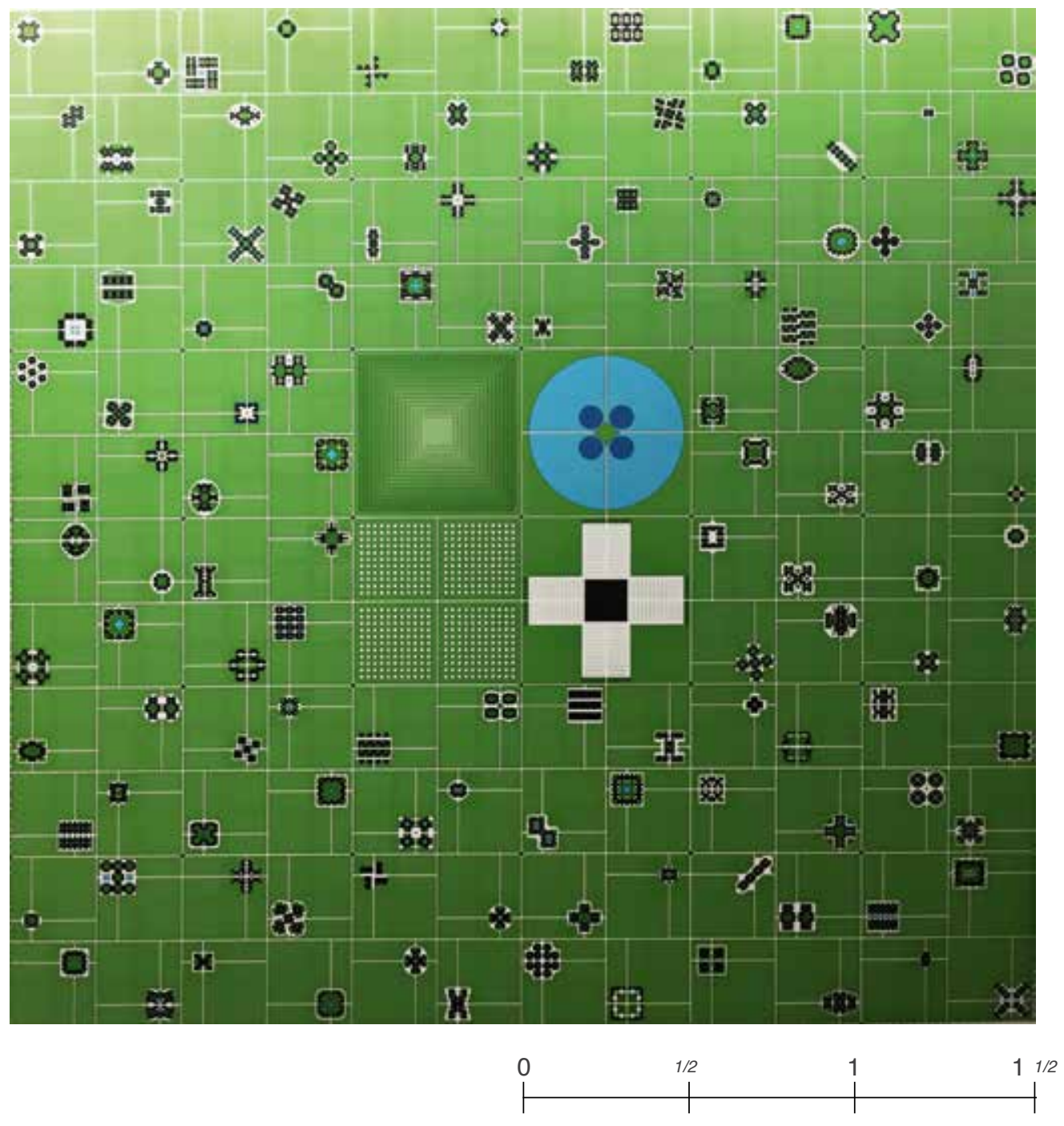

Figure 4. A Purloined Argument, by Keith Krumwiede, New York. "Plan showing a typical three-mile-square town in Freedomland, 2016." (From: exhibition legend.) 


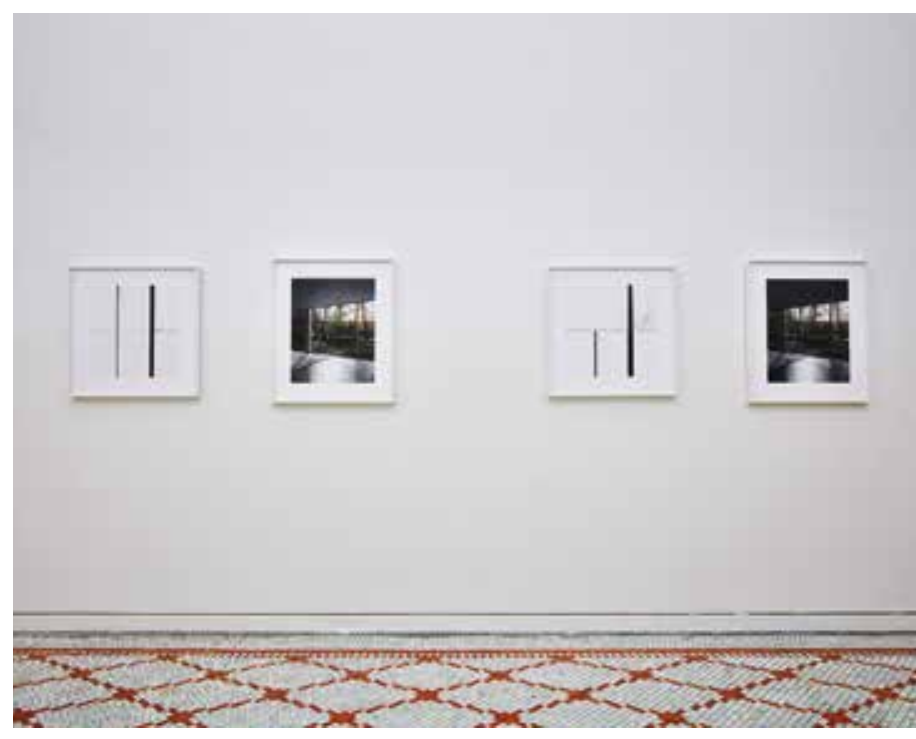

Figure 5. Farnsworth House, by Luisa Lambri. Milan.

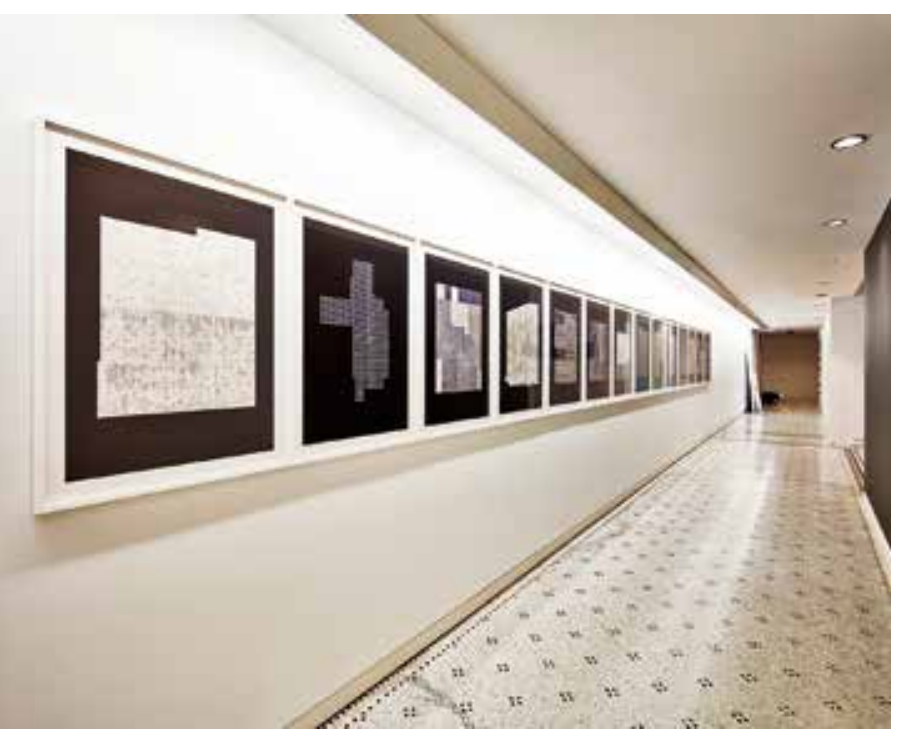

Figure 6. Chicago Series, by Philipp Schaerer, Zurich.

In the opening essay of the catalog, or publication companion of the CAB (which offers additional critical perspectives on a variety of topics, thus augmenting with written essays the cultural contributions offered by the exhibition), Philip Ursprung sheds an interesting light on the relationship between art and architecture in our time. Under the title of "Melancholia Write New Theory," Ursprung's essay describes the experience of a field trip that the author took with students and colleagues from the ETH (Polytechnic of Zurich) across the "heart" of Europe, in the Spring of 2017: from Zurich through Colmar, Strasbourg, the Ardennes, Lille, Dunkirk, the Rhine Delta, up to Rotterdam. While the "melancholic" metaphor helps Ursprung to build an argument for the value of history and theory within the architectural discourse, the journey through places that stirs memories of Europe's past conflicts and current crises (such as Brexit and the wastelands left by the transformations and the evolution of industrial economies), as well as the engagement with current European artists (especially in the field of photography), seems to culminate for the author with an interesting realization:

Art has partially taken the role of architecture theory. It functions as a mirror of architectural practice, making visible its limitations and internal contradictions. Art can function as a medium of architectural critique, in other words as a vantage point from which judgments are made, quality is evaluated, and historical relevance is discussed. The imperative to write new theory requires us to revise our understanding of the current relationship between art and architecture and envision a theory of integration that addresses visual art and architecture alike. ${ }^{8}$ 
Another example of the richness of contributions included in the catalog is Sarah Whiting's essay on the 1950s planning, development and housing story (intertwined with Mies' vision for the IIT campus) for the Chicago Near South Side. Whiting's text is an illuminating discussion of an important moment in the urban history of Chicago (and of urban America in general), with a refreshing re-evaluation of Modern urbanism too superficially and simplistically discarded as the main culprit of all urban crises. In her clearly written "critical story," Whiting makes us appreciate how Mies' basrelief approach to urban design ("where pedestrian movements across campuses, into and through buildings, is fluid and where every building oscillates between being foreground and background and between figure and ground." ${ }^{9}$ ) became an inspiring model for the re-development of the Near South Side. Whiting's final observations raise profound and relevant questions for the future (not the history, new or old) of our field, cities and society:

If the bas-relief of the Near South Side failed in certain aspects, that does not warrant totally abandoning its prescient ifperhaps naively optimistic urban strategy. (...) Seventy-five years after the South Side Planning Board was just beginning to come into existence, how can we find a way to return to its optimism, to its comprehensive mix of constituents that managed nonetheless to produce uncompromised futures, to large visions for the city, and to modern visions for the metropolis? ${ }^{10}$

Was not Mies' IIT campus plan, which inspired the Near South Side planning story, precisely the theoretical key for the unfolding of K. Michael Hays' critical story of his 1984 seminal essay on "critical architecture"? ${ }^{11}$

Also Robert Somol's "conceptual collage" of reference images used by the CAB participants to inspire their own "new histories" (or, better, interpretations) offers an interesting and thought provoking "sectional study" through fundamental issues of our knowledge. Grouping the eighty-four images under four headings, Somol makes us reflect on the meaning of "mood" ("how does the project conspire to reduce or magnify a style of life, for the one or the many?" ${ }^{12}$ ), "manner" ("does the project attempt to deviate the given or naturalize the alien?" ${ }^{13}$ ), "matter" ("is the project materialized through the phenomenal/perceptual or the virtual/conceptual?" ${ }^{14}$ ), and "mode" ("does the project attend to gestalt form or articulated element?" ${ }^{15}$ ).

There are also many other interesting works displayed at the CAB, which, while they don't particularly pose critical questions, do show new levels of design intelligence at various scales and within different contexts. Those include SANAA's beautiful plan (done in collaboration with the IIT College of Architecture) for Bronzeville and the IIT campus; Studio Gang's ingenious 


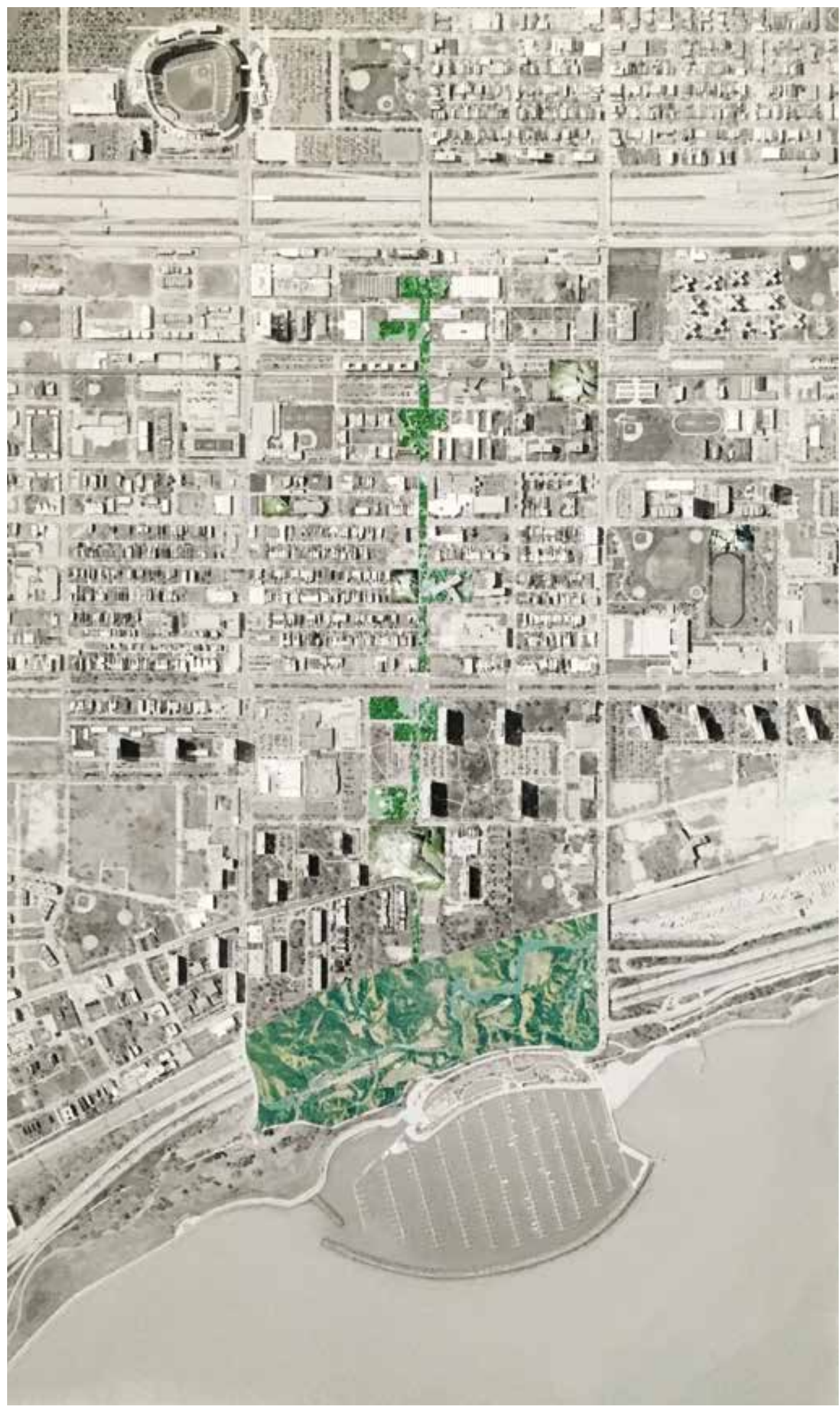

Figure 7. Lake 33rd, Bronzeville, by IIT College of Architecture + SANAA, Chicago + Tokyo. "A proposal of strategic intervention as a series of connectivities between the IIT Mies Campus, Bronzeville, and the lakefront." (From: exhibition legend.) 
"cat-paw" timber construction detail for the Writers Theater in Glencoe (Illinois); the speculative study by Charles Waldheim and his Harvard GSD team (Office for Urbanization), "Heliomorphic Chicago," on the conflicting demands in high-rise buildings for optimizing solar energy exposure, while minimizing the shadows cast on neighboring buildings; or Piovene Fabi's Metropolitana, an intriguing re-interpretation, in terms of objects for a new domestic landscape, of Milan's subway interior and graphic elements designed by Franco Albini and Bob Noorda in the 1960s.

These and other questions, raised by all the interesting contributions included in the catalog, are very important for our field today and we can only thank the CAB (its whole staff, board and international advisory committee) and its 2017 curators, Johnston and Lee, for having given us the opportunity to reflect on them. We should also thank Rahm Emanuel, the Mayor of Chicago, for his support and political vision for such an important event in our field.

True that, as Aaron Betsky pointed out, "a few passing references to Postmodernism in the Jencksian sense of that word, and some flaccid reconstructions of historical models from the Deutsches Architekturmuseum in Frankfurt, Germany, are all that drag this edition away from its repurposing of what is current." ${ }^{16}$ Nevertheless, I do not agree with certain critics, such as Matt Shaw, ${ }^{17}$ who thinks that "the theme forced a generation of emerging architects into a narrow and deadening frame"

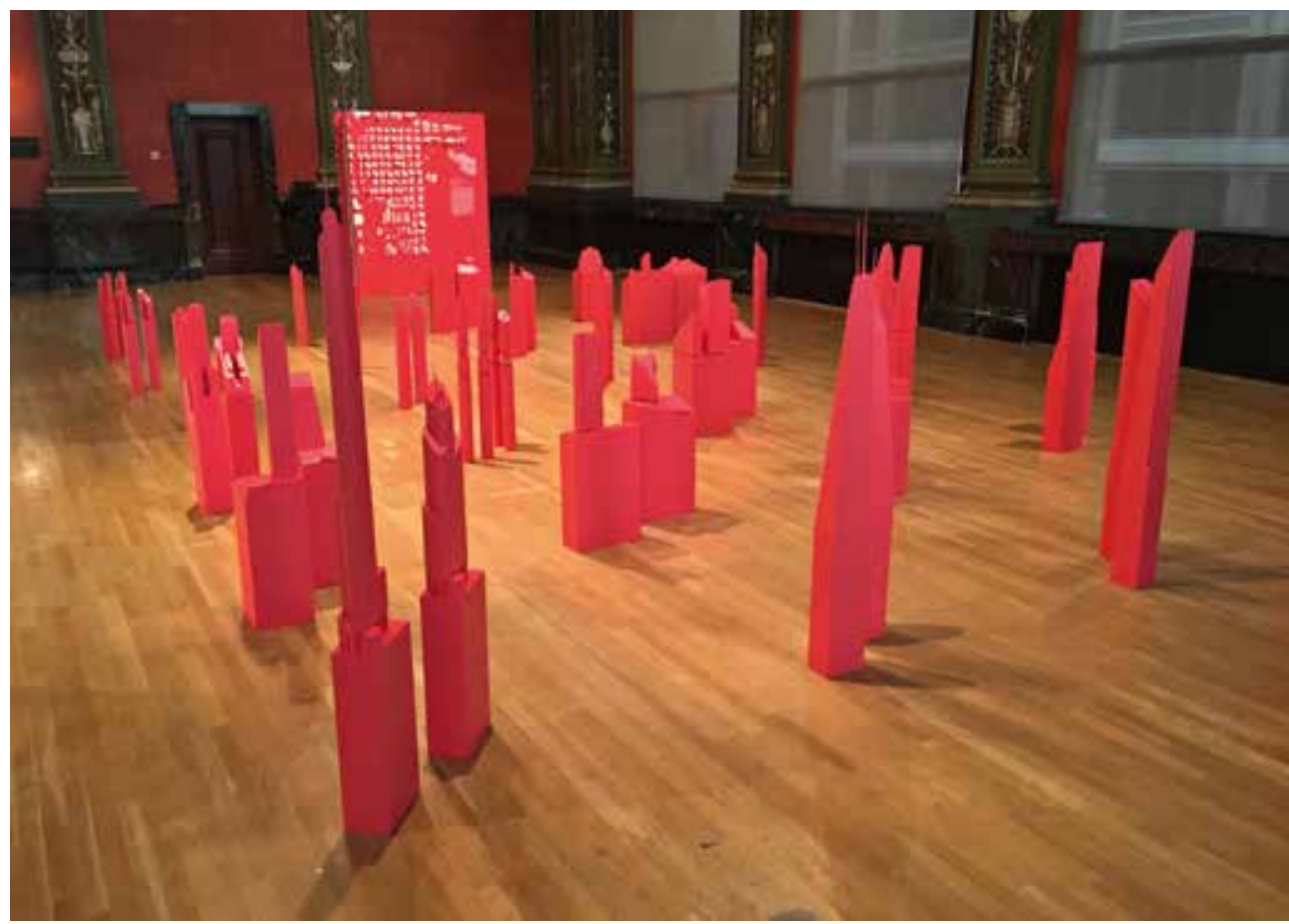

Figure 8. Heliomorphic Chicago, by Charles Waldheim with Office for Urbanization, Harvard Graduate School of Design, and Siena Scarff Design, Cambridge MA (USA). 
(as discussed above, many participants managed to produce intelligent work anyway) or that the "history [presented] was stale and familiar, and largely irrelevant today" (some of the histories at the show, capable to generate intriguing interpretations, even though not always of critical power, remain as inspirational as ever, such as Superstudio's visions and, yes, Mies - can Mies be considered "stale"?).

I do agree with Shaw, though, that the danger of this CAB is to see, once again, "the complexity of history reduced to precedent" - but this is not a particular flaw of this $\mathrm{CAB}$, as it is a flaw of our general architectural culture, primarily nurtured in architecture schools, offspring of the "legalistic" character of our society (a precedent is the basis to support a legal argument in court). As I discussed elsewhere, ${ }^{18}$ history is not a "quality certificate" for a design nor a catalog to borrow from or where to digitally "copy \& paste \& photoshop." It is a cultural bedrock that we need, for mature, substantial, narrative-wise "thick," new designs, ideas, visions (not "new histories": if anything, "new stories"). History cannot be superficially intended as a "treasure trove." History is the necessary "ladder" than one has to climb, in order to reach a higher level of discourse and narrative, but one that needs to be abandoned, because not directly useful when immersing oneself in the (modern) design process. Thus Mimi Zeiger's critique to this $\mathrm{CAB}$ is on the mark when she observes that "if architecture as intellectual inquiry (biennials, academy, books) and profession (high rises, houses, mini-malls) is to continue to carry meaning, it needs to take

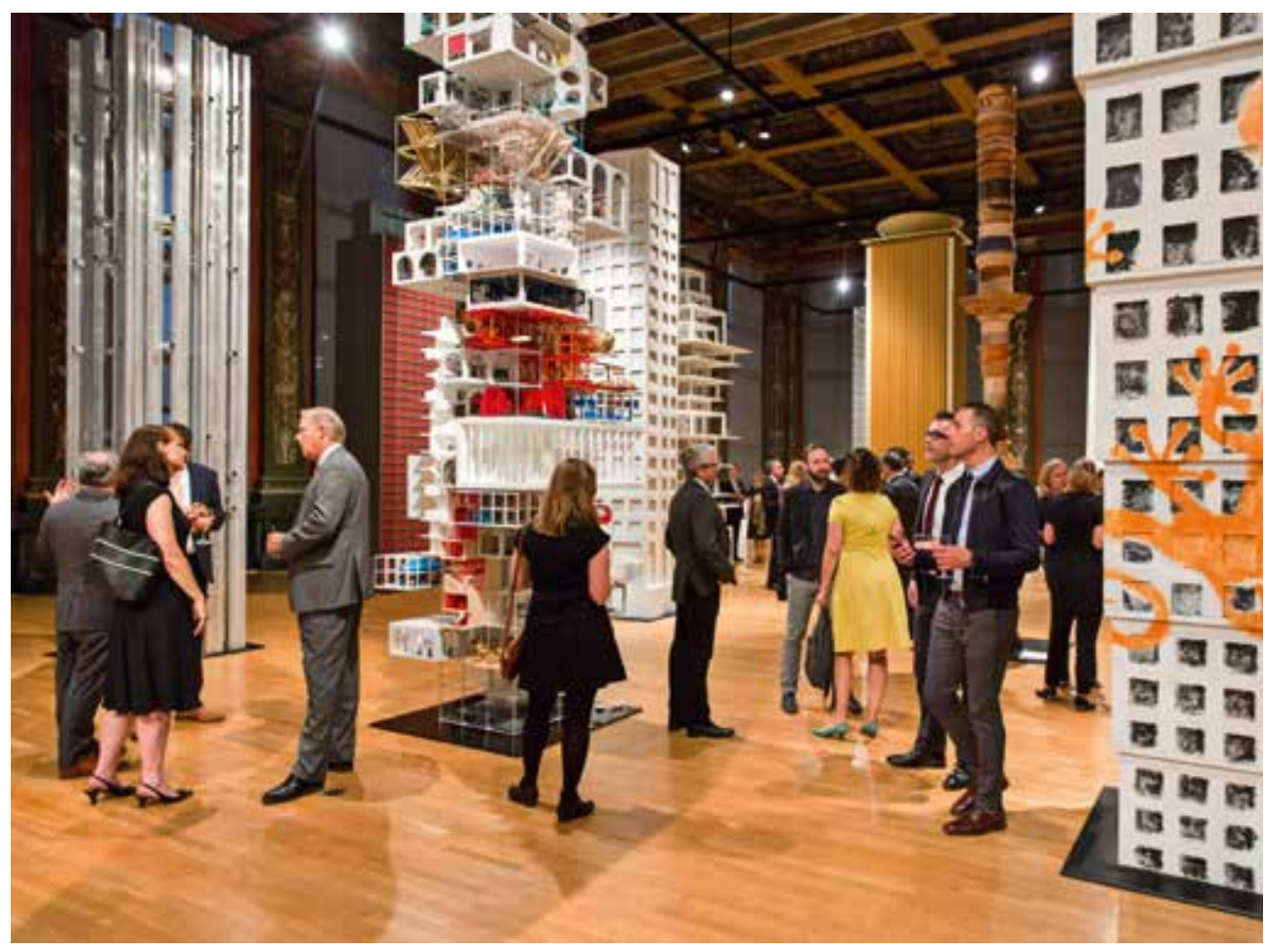

Figure 9. CAB opening night, September 14, 2017. 
more risks and find allies in resistance. History - new, now, and otherwise has never been a safe space." 19

The $\mathrm{CAB}$, and this edition more than ever, is an important event: globally, regardless of the fact that it has little to do with Chicago, even though some satellite exhibitions offer also that - such as the documentation of the fascinating geological history and remarkably rich Modern architectural heritage of one of Chicago's southern neighborhood, Beverly/Morgan Park, at the Beverly Arts Center. When invited to participate in the first 2015 edition of the $C A B$, the French firm of Lacaton \& Vassal enthusiastically accepted, commenting "Chicago is so important to us because we are modern." ${ }^{20}$ Chicago is the quintessential laboratory for Modern architecture and urbanism and this ethos is sufficient to justify the location of this biennial. As observed by Vassallo in the catalog:

Nowhere as in Chicago, a place where the myth of modernity and the building stock of the city become almost one and the same thing, can we find better reasons to put forward an informed argument for engaging the material world in all its breadth - an optimistic proposal for the future..$^{21}$

The CAB has already become (even though it should grow more into) an unavoidable moment of exchange of ideas, positions and visions for the evolution of our field. As pointed out by Johnston, "the Biennial format sits at the core of architecture's cultural project: a forum to reach and produce new audiences." 22 Yet, it could further sharpen its purpose moving forward: provoking more meaningful debates with more critical positions, thus recapturing architecture's call to be a powerful, critical voice for our culture and society.

\section{Notes}

1. "Chicago Hope," interview by Janelle Zara with 2017 CAB Artistic Directors Mark Lee and Sharon Johnston, ArtForum, September 21, 2016, https://www.artforum.com/slant/ id $=63556$

2. "From the First Biennial to the Second and Back Again," interview by Sarah Herda, Co-Artistic Director of the inaugural 2015 Chicago Architecture Biennial, with 2017 Artistic Directors Mark Lee and Sharon Johnston, in Make New History. 2017 Chicago Architecture Biennial, eds. Mark Lee, Sharon Johnston, Sarah Hearne, and Letizia Garzoli (Baden, Switz.: Lars Müller Publishers, 2017), 19-27 (20).

3. Christopher Hawthorne, "'Make New History,' the Second Chicago Architecture Biennial, Brings the Focus Back to Square One," Los Angeles Time, September 22, 2017, http://www. latimes.com/entertainment/arts/la-et-cm-chicago-architecture-biennial-review-20170922htmlstory.html.

4. Sharon Johnston, "From the First Biennial...," in Make New History, 25.

5. Aaron Betsky, "Beauty that Is Neither New Nor Historical," Architect, September 29,

2017, http://www.architectmagazine.com/design/beauty-that-is-neither-new-nor-historical_o.

6. Jesús Vassallo, "A Love of the World," in Make New History, 183-189 (183).

7. Ibid., 183.

8. Philip Ursprung, "Melancholia - Write New Theory," in Make New History, 29-35 (34). 
9. Sarah Whting, "Figuring Modern Urbanism: Chicago's Near South Side," in Make New History, 89-99 (93).

10. Ibid., 99.

11. K. Michael Hays, "Critical Architecture: Between Culture and Form,"

Perspecta 21 (1984): 14-29.

12. "Mood, Matter, Manner, Mode," curated by Robert Somol, in Make New History,

313-325 (314)

13. Ibid., 317.

14. Ibid., 320.

15. Ibid., 323.

16. Betsky, "Beauty that Is Neither New Nor Historical."

17. Matt Shaw, "Five fundamental problems with the 2017 Chicago Architecture Biennial," Architect's Newspaper, September 21, 2017, https://archpaper.com/2017/09/5-problemschicago-architecture-biennial/ .

18. Maurizio Sabini, "Wittgenstein's Ladder. The Non-Operational Value of History in Architecture," Journal of Architectural Education 64, no. 2, (March 2011): 46-58.

19. Mimi Zeiger, "Architecture as intellectual inquiry needs to take more risks," Dezeen, September 26, 2017, https://www.dezeen.com/2017/09/26/opinion-mimi-zeiger-secondchicago-architecture-biennial/ .

20. As reported by Mark Lee, "From the First Biennial...," 21.

21. Vassallo, "A Love of the World," 189.

22.. Johnston, "From the First Biennial...," 26.

\section{Credits}

Figures 1-4, 7 and 8: Photos by the Author, reproduced courtesy of Chicago Architecture Biennial.

Figure 5: Courtesy of Chicago Architecture Biennial, Steve Hall @ Hall Merrick Photographers.

Figure 6: Courtesy of Chicago Architecture Biennial, (c) Tom Harris.

Figure 9: Courtesy of the Chicago Architecture Biennial.

Photographer: Benjamin Lozovsky/BFA.com. 